Tennis, J. T. (2007). The economic and aesthetic axis of information organization frameworks. (extended abstract). Proceedings of the North American Symposium on Knowledge Organization. Vol. 1. Available:

http://dlist.sir.arizona.edu/1915

Joseph T. Tennis

The University of British Columbia, Vancouver, British Columbia, Canada

\title{
The economic and aesthetic axis of information organization frameworks
}

Extended abstract for the position paper submitted to the North American Symposium on Knowledge Organization (NASKO), Toronto, Ontario, 2007. Full paper to appear in Knowledge Organization vol. 34 no. 2 (2007).

Extended abstract: When we examine how and why decisions get made in the indexing enterprise writ large, we see that two factors shape the outcome: economics and aesthetics. For example, the Library of Congress has reduced the time and effort it has spent on creating bibliographic records, while the Library and Archives Canada has begun coordinating the work of librarians and archivists in describing the documentary heritage of Canada (Oda and Wilson, 2006; LAC, 2006). Both of these initiatives aim at reducing costs of the work of description. They are decisions based on economic considerations. When engaged in deciding what fields, tags, and indicators to use in cataloguing, librarians consider the cost of labour and whether or not the system will use that work for display and retrieval.

On the other hand, international bodies craft standards that are designed to shape the indexing enterprise. For example, we see the form of controlled vocabularies in ANSI/NISO Z39.19-2005. We then evaluate such vocabularies as to whether or not they comport with that form. This is one interpretation of the aesthetic consideration of indexing. We can take this further. We can look at indexing theory and, for example the work of Ranganathan and the $\mathrm{CRG}$, and compare instantiations of classification schemes as to whether or not they are truly faceted.

These examples result from designers and implementers of description and identification systems asking: what is good enough? When is my framework for information organization good enough? Though each of these acts is governed by a different purpose (sometimes pragmatic, sometimes artistic), the acts involved, the identification and description of resources, is measured against both economic and aesthetic concerns: how much does it cost, and how well does it comply with an abstract form, how is it evocative of our human urge to name and organize?

Information organization frameworks, like those discussed above, comprise structures, work practices, and discourses. Examples of structure would be: the bibliographic record, the archival description, and the list developed by the patrons of the art installation. Work practices enable, result in, and evaluate structures, and the discourse shapes how priorities and purposes are aligned in both work practices and structures. Key to all examples of and components of 
Tennis, J. T. (2007). The economic and aesthetic axis of information organization frameworks. (extended abstract). Proceedings of the North American Symposium on Knowledge Organization. Vol. 1. Available:

Information Organization Frameworks are considerations of cost and compliance with abstract form (standardization or design).

This paper explores the diversity of information organization frameworks, looking specifically at how aesthetic concerns and economic concerns manifest their work practices, structures, and discourse. In order to do this I examine the manuals and policies that shape work practice, the structures and their paratextual material (introductions, how-to-use guides, etc.), and the literature that references these practices and structures. I take the position that we need to move into a more descriptive stance on practices of knowledge organization, not only in documentary heritage institutions (libraries, archives, and museums), but also into the cultural and artistic realms. By expanding the scope of inquiry we can interrogate the integrity of my assertion above that information organization frameworks wrestle with, and manifest along a spectrum drawn from economic to aesthetic decision-making.

This project, investigating the economic-aesthetic axis of information organization frameworks, follows the recent development in knowledge organization research, which is moving from prescriptive (how to design systems) to a descriptive (what systems are being built, how and why) approach, (Beghtol, 2003; Andersen, 2005). By engaging in this work, we grow more familiar with not only the professional concerns with knowledge organization, but rather, expand the scope of our inquiring into the knowledge organization practices for various purposes, and develop a deeper understanding of the human urge to name and organize.

\section{References}

Andersen, J. (2005). SIG/CR Call for Papers for the 2005 Workshop. http://www.isrl.uiuc.edu/ klabarre/sigcr/

Beghtol, C. (2003). Classification for information retrieval and classification for knowledge discovery: relationships between "professional" and "naïve" classifications. Knowledge Organization 30: 64-73.

LAC. (2006). New Directions in Description: Metadata Management in Theory and Practice. http://www.collectionscanada.ca/webcast/n3-213-e.html

Oda, B. J. and Wilson, I. (2006) Department Performance Report 2005-2006, Library and Archives Canada. http://www.tbs-sct.gc.ca/dpr-rmr/0506/LAC-BAC/lac-bac_e.pdf 